\title{
PENGARUH PELATIHAN TERHADAP EFISIENSI KERJA KARYAWAN PADA KOPERASI SETIA USAHA OKU TIMUR
}

\author{
Oleh: Winda Feriyana \\ (STIE TRISNA NEGARA) \\ feriyanawinda@gmail.com
}

\begin{abstract}
Abstrak-Penelitian ini adalah Untuk mengetahui besarnya pengaruh pelatihan terhadap efisiensi kerja karyawan. Teknik pengumpulan data dilakukan dengan cara wawancara, observasi, dokumentasi, dan kuisioner serta studi kepustakaan. Dari hasil perhitungan diperoleh $r=0,614$. Setelah dikonsultasikan dengan standar konservatif untuk mengetahui erat atau tidaknya hubungan tersebut ternyata $r=0,614$ terletak pada jarak antara 0,600 - 0,799 yang termasuk pada korelasi kuat. Berarti menunjukkan adanya pengaruh yang besar terhadap efisiensi kerja karyawan melalui pelatihan. Kemudian untuk menjawab uji hipotesis yang diajukan pada bab sebelumnya mempunyai hubungan atau tidak, maka di uji dengan uji hipotesa dan didapat thitung $=2$ 202. Sedangkan nilai $t$ tabel pada tingkat kepercayaan 95\% untuk $(n-2)=2,013$. Maka dapat diketahui nilai $t$ hitungnya 2,202 lebih besar dari pada nilai $t$ tabel yaitu $=2,013$, dengan demikian berarti ( $\mathrm{Ha}$ ) dapat diterima dan ( $\mathrm{Ho}$ ) ditolak. Kesimpulan dari penelitian tersebut adanya pengaruh yang kuat antara pelatihan terhadap efisiensi kerja karyawan pada Koperasi Setia Usaha OKU Timur
\end{abstract}

Kata Kunci : Pelatihan, Efisiensi

\begin{abstract}
This study was to determine the effect of training on employee work efficiency. Data collection techniques carried out by interview, observation, documentation, and questionnaires and literature study. From the calculation results obtained $r=0.614$. After consultation with conservative standards to find out whether the relationship is close or not, it turns out that $r=0.614$ is located at a distance between 0.600 - 0.799 which is included in the strong correlation. Means showing a great influence on employee work efficiency through training. Then to answer the hypothesis test proposed in the previous chapter has a relationship or not, then tested with a hypothesis test and obtained $t$ count $=$ 2.202. While the value of t table at 95\% confidence level for $(n-2)=2.013$. Then it can be seen that the $t$ value of 2.202 is greater than the value of t table that is $=$ 2.013, thus it means that ( $\mathrm{Ha}$ ) can be accepted and (Ho) rejected. The conclusion of the study is the strong influence between training on employee work efficiency at the East OKU Setia Usaha Cooperative
\end{abstract}

Keywords: Training, Efficiency 
PENDAHULUAN

Mangkuprawira
menyatakan Pelatihan $r$ bagi
karyawan merupakan sebuah proses
mengajarkan pengetahuan dan
keahlian tertentu serta sikap agar
karyawan semakin baik sesuai
dengan standart. Menurut Sulistyani
\& Rosidah (2003) pelatihan
adalah $\quad$ proses sistematik pengubahan perilaku para pegawai dalam suatu arah guna meningkatkan tujuan organisasi, Pelatihan dan Pengembangan penting karena keduanya merupakan cara untuk mempertahankan, menjaga, memelihara dan meningkatkan keahlian para pegawai. Sedangkan menurut Gomes ( 2003) Pelatihan adalah setiap usaha untuk memperbaiki performance pekerja pada suatu pekerjaan tertentu yang sedang menjadi tanggung jawabnya.

Sedangkan efisiensi berkaitan dengan menghasilkan sesuatu / produksi yang optimal dengan tidak membuang sumber daya dalam proses pengerjaannya. Bekerja dengan efisien adalah bekerja dengan gerakan, usaha, waktu dan tenaga yang sedikit mungkin dengan hasil yang tetap sama. Cara bekerja yang efisien dapat diterapkan oleh semua karyawan untuk semua pekerjaan yang kecil maupun yang besar sehingga dapat membantu mempercepat penyelesaian tugas dengan menghemat tenaga, waktu, biaya, bahan dan lainnya. Oleh karena itu perusahaan harus memberikan pelatihan terhadap karyawan demi peningkatan kemampuan dasar karyawan agar meningkatkan efisiensi kerja dalam pelaksanaan operasional kerja pegawai.

Perusahaan perlu menerapkan suatu sistem yang tepat untuk dapat menjaga keberlangsungan kegiatan operasionalnya. Pelatihan sering dianggap sebagai aktifitas yang paling dapat dilihat dan paling umum dari semua aktifitas kepegawaian. Para atasan menyokong pelatihan karena melalui pelatihan para karyawan akan menjadi lebih trampil, dan karenanya lebih produktif, sekalipun manfaatmanfaat tersebut harus diperhitungkan dengan waktu yang akan dikeluarkan ketika para karyawan sedang dilatih. Oleh karena itu, dengan adanya pelatihan yang diberikan oleh perusahaan dapat menimbulkan kemampuan kepada karyawannya. Metode pelatihan mempunyai beberapa macam dan penggunaannya seringkali disesuaikan dengan kondisi perusahaan. Metode pelatihan Sumber Daya Manusia yang sering digunakan antara lain metode On The Job Training yaitu pegawai mempelajari pekerjaannya dengan mengamati pekerja lain yang sedang bekerja, dan kemudian mengobservasi perilakunya, dan ada juga Off The Job Training yaitu mempelajari suatu pekerjan diluar jam kerjanya. 


\section{METODE PENELITIAN}

\section{Sumber Data}

1. Data Primer

Yaitu suatu data yang diperoleh secara langsung dari kegiatan penelitian. Data dikumpulkan dari responden dengan wawancara atau mengisi daftar pertanyaan yang telah dipersiapkan.

\section{Data Sekunder}

Yaitu suatu data yang diperoleh dari luar penelitian yang berasal dari buku-buku penelitian yang ada hubungannya dengan penelitian yang dilakukan.

\section{Pengumpulan Dan Pengolahan}

\section{Data}

1. Penelitian Kepustakaan ( Library Research )

Yaitu pengumpulan data dengan mempelajari berbagai macam literatur, buku-buku ilmiah yang berkaitan dengan penelitian.

2. Penelitian Lapangan ( Field Research )

Yaitu penelitian yang langsung datang ke objek penelitian untuk melihat dan meneliti secara langsung. Dilakukan dengan cara:

a. Observasi

Yaitu pengumpulan data dengan cara pengamatan langsung dilokasi penelitian yaitu pada Koperasi Setia Usaha OKU Timur.

b. Quisioner

Pengumpulan data dengan cara memberikan daftar pertanyaan kepada pimpinan atau karyawan pada Koperasi Setia Usaha OKU Timur.

c. Interview

Yaitu pengumpulan data dengan mengadakan wawancara langsung peneliti dengan pimpinan dan karyawan yang dianggap memberikan informasi yang dibutuhkan dalam penelitian.

d. Dokumentasi

Yaitu data yang diperoleh dengan melihat dokumen atau catatan - catatan yang berhubungan dengan penelitian.

\section{Analisis Data}

1. Analisis Kualitatif

Analisis yang digunakan untuk memecahkan permasalahanpermasalahan yang ada dengan tidak menggunakan angka-angka sebagai dasar pertimbangan, tetapi dengan menggunakan kalimatkalimat yang menjelaskan tentang keadaan Koperasi Setia Usaha OKU Timur.

2. Analisis Kuantitatif

Yaitu suatu analisis yang menggunakan angka-angka yang bertujuan untuk mengetahui besar kecilnya pengaruh pelatihan terhadap efisiensi kerja karyawan pada Koperasi Setia Usaha OKU Timur. 


\section{HASIL DAN PEMBAHASAN}

Alat analisis yang digunakan dalam analisis kuantitatif adalah menggunakan rumus Korelasi Product Moment yang rumusnya sebagai berikut yaitu :

$$
r=\frac{n \sum x i \cdot y i-\left(\sum X i\right)\left(\sum Y i\right)}{\sqrt{\left(n \cdot \sum X i^{2}-\left(\sum X\right)^{2}\right\}} \sqrt{\left\{n \cdot \sum Y i^{2}-\left(\sum Y\right)^{2}\right\}}}
$$

(Anto Dajan, 2008 :376 )

Keterangan :

$$
\begin{aligned}
\sum= & \text { Jumlah } \\
\mathrm{r}= & \text { Koefisien korelasi antara } \mathrm{x} \\
& \text { dan } \mathrm{y} \\
\mathrm{X}= & \text { Variabel Pelatihan } \\
& \text { variabel bebas })
\end{aligned}
$$

$$
\begin{aligned}
& \mathrm{Y}=\text { Variabel Efisiensi Kerja } \\
& \text { (variabel terikat ) } \\
& \mathrm{n}=\text { Banyaknya sample } \\
& \mathrm{X}^{2}=\text { Hasil kuadrat variabel } \\
& \mathrm{Y}^{2}=\text { Hasil kuadrat variabel } \\
& \mathrm{Xy}=\text { Hasil perkalian antara } \\
& \text { variabel bebas dan terikat }
\end{aligned}
$$

Untuk mengetahui besar kecilnya korelasi yang timbul antara pelatihan ( $\mathrm{x}$ ) dan efisiensi kerja pegawai ( $\mathrm{y}$ ), untuk itu penulis menggunakan pedoman Interprestasi Koefisien Korelasi yang dapat dilihat pada tabel 1 sebagai berikut :

\section{Tabel 1. Interpretasi Koefisien Korelasi}

\begin{tabular}{|c|c|}
\hline Interval Koefisien & Tingkat Hubungan \\
\hline $0,00-0,199$ & Sangat rendah \\
$0,20-0,399$ & Rendah \\
$0,40-0,599$ & Sedang \\
$0,60-0,799$ & Kuat \\
$0,80-1,000$ & Sangat kuat \\
\hline
\end{tabular}

(Sugiyono, $2009: 183$ )

Untuk mengetahui besar kecilnya korelasi yang timbul antara pelatihan ( $\mathrm{x}$ ) dengan efisiensi kerja ( $\mathrm{Y}$ ) maka harus mengetahui kadar persentase ( \% ) dengan menggunakan rumus :

$$
\mathrm{KP}=\mathrm{r}^{2} \mathrm{x} 100 \% \text {. }
$$

Setelah diketahui kadar persentase yang dipengaruhi maka ada faktor lain yang mempengaruhi dengan menggunakan rumus :

$$
100 \%-\mathrm{KP}
$$

Untuk menguji hipotesis yang telah diuraikan dapat atau tidaknya diterima, maka penulis menggunakan rumus :

$$
t=\frac{r \sqrt{n-2}}{\sqrt{1-r^{2}}}(\text { Riduwan, 2010:229) }
$$

\section{Keterangan :}

$\mathrm{t}=$ Pengujian koefisien korelasi

$r=$ Koefisien korelasi

$\mathrm{n}=$ Jumlah sample

" $\mathrm{t}$ " dapat dicari dengan melihat tabel " $\mathrm{t}$ " dengan derajat kebebasan 0,05 untuk $(\mathrm{n}-2)$, apabila $\mathrm{t}>\mathrm{t}(\mathrm{n}$ 
- 2) maka Ha di terima dan Ho di tolak tetapi apabila $\mathrm{t}<\mathrm{t}(\mathrm{n}-2)$ maka Ha di tolak dan Ho di terima.

Sebelum dimasukkan ke dalam rumus yang telah ditentukan sebelumnya, maka hasil penelitian dari angket yang telah disebarkan kepada responden, ditabulasikan ke dalam bentuk tabel dengan penilaian dari setiap jawaban yang diberikan oleh responden sebagai berikut :
a. Alternatif jawaban A di beri score 3
b. Alternatif jawaban B di beri score 2
c. Alternatif jawaban $\mathrm{C}$ di beri score 1

\section{Landasan Teori}

Secara umum pelatihan merupakan bagian dari pendidikan yang menggambarkan proses dalam pengembangan organisasi maupun masyarakat. Pendidikan dan pelatihan merupakan suatu rangkaian yang tak dapat dipisahkan dalam system pengembangan sumber daya manusia, yang didalamnya terjadi proses perencanaan, penempatan dan pengembangan tenaga manusia. Dalam proses pengembangannya diupayakan agar sumber daya manusiadapat diberdayakan secara maksimal, sehingga apa yang menjadi tujuan dalam memenuhi kebutuhan hidup manusia dapat terpenuhi.

Ada anggapan bahwa dengan digalakkan latihan akan menimbulkan pemborosan karena dianggap bisa mempertinggi biaya dalam pencapaian tujuan perusahaan. Anggapan tersebut salah karena justru dengan adanya latihan akan terjadi penghematan. Misalnya: peralatan yang canggih dan mahal apabila ditangani oleh tenaga yang kurang terlatih justru menimbulkan biaya yang sangat besar jika terjadi kerusakan. Maksudnya ingin menghemat malah menghasilkan pemborosan. Hasil dari penggalakkan latihan ini memang tidak dirasakan secara langsung karena merupakan investasi jangka panjang.

Sedangkan "pelatihan merupakan bagian dari pendidikan yang menyangkut proses belajar untuk memperoleh dan meningkatkan ketrampilan di luar sistem pendidikan yang berlaku, dalam waktu yang relative singkat dan dengan metode yang lebih mengutamakan praktek dari pada teori."

$\begin{array}{ccc}\text { Dengan } & \text { demikian } & \text { usaha } \\ \text { peningkatan } & \text { pegawai } & \text { agar }\end{array}$ berkualitas baik mental maupun kemampuan tidak boleh diabaikan. Dan latihan itu sendiri digalakkan bukan hanya pada pegawai-pegawai baru tetapi juga pada pegawai yang lama karena adanya tuntutan dari tugas-tugas yang sekarang, ataupun untuk kenaikkan pangkat.

\section{Efisiensi Kerja}

Kata ini memiliki beberapa arti tergantung dari penggunaan serta 
topik yang sedang dibahas. Dalam kamus besar bahasa Indonesia (KBBI) memiliki arti umum yang dibagi menjadi dua. Dalam definisi yang pertama efisiensi diartikan sebagai ketepatan cara dalam menjalankan sesuatu atau dapat disingkat kedayagunaan dan ketepatgunaan.

Dalam definisi kedua efisiensi diartikan sebagai kemampuan menjalankan tugas dengan baik dan tepat tanpa membuang waktu, tenaga maupun biaya. Dalam arti kedua ini ada penekanan lebih terhadap bagian "tanpa membuang..."

Dari segi ekonomi, efisiensi sering dibahas dalam proses produksi. Proses produksi secara umum adalah tahap - tahap yang harus dilalui barang sebelum nantinya dipasarkan. Proses produksi terdiri dari input (berupa bahan, resource, pekerja dan bahkan modal) yang akan dibentuk menjadi output (barang jadi atau hasil produksi) setelah melalui proses - proses tertentu.

Efisiensi dalam hal proses produksi adalah hal yang ingin dicapai untuk mendapatkan keuntungan yang banyak. Efisiensi di sini berfokus pada penggunaan input secara minimalis namun tetap menghasilkan target output yang diinginkan.

Banyak para ahli yang mencoba mengartikan kata efisiensi dari segi ekonomi ini dengan pandangan mereka sendiri. Berikut adalah dua pemahaman efisiensi dari para ahli ekonomi yang cukup terkenal:

1. Mulyamah mengartikan bahwa "Efisiensi adalah sebuah ukuran dalam membandingkan antara rencana penggunaan masukan dengan penggunaan yang direalisasikan atau perkataan lain penggunaan yang sebenarnya."

2. Sedangkan SP.Hasibuan (1984;233-4) mengutip pernyataan dari H. Emerson yang mengatakan bahwa "Efisiensi merupakan perbandingan yang terbaik antara sebuah input (masukan) dan output (hasil antara keuntungan dengan sumbersumber yang dipergunakan), seperti halnya juga hasil optimal yang telah dicapai dengan penggunaan sumber yang terbatas. Jadi bisa dikatakan hubungan antara apa yang telah diselesaikan."

Untuk menerapkan efisiensi dalam bekerja ini karyawan perlu mengetahui asas-asas efisiensi bagi pekerjaan yaitu sebagai berikut :

\section{Azas}

Perencanaan.

Perencanaan berarti menggambarkan suatu tindakan yang akan dilaksanakan dalam rangka mencapai suatu tujuan. Perencanaan ini sangat penting agar efisiensi dapat dilakukan 
karena tindakan apa yang akan dilakukan telah direncanakan sebelumnya.

2. Azas Penyederhanaan. Menyederhanakan berarti membuat suatu sistem yang rumit atau pekerjaan yang sukar menjadi lebih mudah atau ringan.

3. Azas Penghematan. Menghemat berarti mencegah pemakaian benda/bahan secara berlebihan sehingga biaya pekerjaan menjadi lebih minim

4. Azas Penghapusan. Menghapuskan berarti meniadakan kegiatan yang memiliki persamaan kegiatan atau bahan yang mungkin dapat dikerjakan sekaligus dalam satu langkah sehingga dapat menghemat waktu kerja.

5. Azas

Penggabungan.

Menggabungkan berarti menyatukan pekerjaan yang memiliki persamaan kegiatan atau bahan yang mungkin dapat dikerjakan sekaligus dalam satu langkah sehingga dapat menghemat waktu kerja.

Untuk mencapai efisiensi kerja tersebut diperlukan beberapa syarat berikut ini :

1. Berhasil Guna atau Efektif. Syarat ini menyatakan bahwa kegiatan telah dilaksanakan dengan tepat, dalam arti target tercapai sesuai dengan waktu yang ditetapkan.

2. Ekonomis. Syarat ekonomis menyatakan bahwa dalam usaha mencapai sesuatu yang efektif biaya, tenaga kerja, material, peralatan, waktu, dan ruangan telah dimanfaatkan dengan tepat.

3. Pelaksanaan Kerja yang Dapat

Dipertanggungjawabkan.

Syarat ini untuk membuktikan bahwa dalam pelaksanaan kerja sumbersumber yang ada telah dimanfaatkan dengan tepat dan dapat dipertanggungjawabkan

4. Pembagian Kerja yang Nyata. Manusia mempunyai kemampuan yang terbatas sehingga tidak mungkin mengerjakan segala macam pekerjaan dengan baik. Hendaknya ada pembagian kerja yang nyata berdasarkan beban kerja, ukuran kemampuan kerja dan waktu yang tersedia.

5. Rasionalitas Wewenang dan Tanggung Jawab. Wewenang harus seimbang dengan tanggung jawab seseorang, artinya jangan sampai terjadi seseorang mempuyai wewenang yg lebih besar dari tanggung jawab atau sebaliknya jangan sampai terjadi wewenang 
lebih kecil dari tanggung jawabnya.

6. Prosedur Kerja yang Praktis. Artinya bahwa peleksanaan kerja harus merupakan kegiatan operasional yang dapat di laksanakan dengan lancar , dapat dipertanggungjawabkan serta pelayanan kerja yang memuaskan.

\section{Analisis Data}

Untuk analisa ini dipergunakan alat bantu tabel dan rumus koefisien korelasi, dengan langkah awalnya yaitu tabel yang diperoleh dari jawaban angket penelitian mengenai pengaruh antara pelatihan terhadap efisien kerja karyawan pada Koperasi Setia Usaha OKU Timur. Dengan demikian langkah kerjanya dapat dilihat pada tabel-tabel berikut :

Tabel 2. Variabel ( X ) Pelatihan

\begin{tabular}{|c|c|c|c|c|c|c|}
\hline \multirow{2}{*}{ Responden } & \multicolumn{5}{|c|}{ Nomor Pertanyaan } & \multirow{2}{*}{ Jumlah } \\
\cline { 2 - 6 } & $\mathbf{1}$ & $\mathbf{2}$ & $\mathbf{3}$ & $\mathbf{4}$ & $\mathbf{5}$ & \\
\hline 1 & 2 & 3 & 2 & 2 & 2 & 11 \\
2 & 3 & 1 & 3 & 3 & 3 & 13 \\
3 & 3 & 2 & 1 & 2 & 2 & 10 \\
4 & 3 & 3 & 2 & 3 & 3 & 14 \\
5 & 3 & 3 & 1 & 3 & 3 & 13 \\
6 & 3 & 3 & 2 & 1 & 2 & 11 \\
7 & 3 & 3 & 2 & 3 & 1 & 12 \\
\hline Jumlah & \multicolumn{7}{|l}{} & $\mathbf{8 4}$ \\
\hline
\end{tabular}

Sumber : Data Diolah

Tabel 3. Variabel ( Y ) Efisiensi Kerja Karyawan

\begin{tabular}{|c|c|c|c|c|c|c|}
\hline \multirow{2}{*}{ Responden } & \multicolumn{5}{|c|}{ Nomor Pertanyaan } & \multirow{2}{*}{ Jumlah } \\
\cline { 2 - 6 } & $\mathbf{1}$ & $\mathbf{2}$ & $\mathbf{3}$ & $\mathbf{4}$ & $\mathbf{5}$ & \\
\hline 1 & 3 & 1 & 3 & 3 & 3 & 13 \\
2 & 3 & 3 & 2 & 2 & 3 & 13 \\
3 & 3 & 3 & 1 & 3 & 1 & 11 \\
4 & 3 & 3 & 2 & 3 & 2 & 13 \\
5 & 3 & 3 & 3 & 1 & 2 & 12 \\
6 & 3 & 1 & 2 & 3 & 1 & 10 \\
7 & 3 & 2 & 1 & 1 & 2 & 9 \\
\hline Jumlah & \multicolumn{7}{|c|}{} & $\mathbf{8 1}$ \\
\hline
\end{tabular}

Sumber : Data Diolah 
Tabel 4. Korelasi Variabel X (Pelatihan) dan Variabel Y (Efisiensi Kerja)

\begin{tabular}{|c|c|c|c|c|c|}
\hline No. & $\mathbf{X}$ & $\mathbf{Y}$ & $\mathbf{X}^{\mathbf{2}}$ & $\mathbf{Y}^{\mathbf{2}}$ & $\mathbf{X . Y}$ \\
\hline 1 & 11 & 13 & 121 & 169 & 143 \\
2 & 13 & 13 & 169 & 169 & 169 \\
3 & 10 & 11 & 100 & 121 & 110 \\
4 & 14 & 13 & 196 & 169 & 182 \\
5 & 13 & 12 & 169 & 144 & 156 \\
6 & 11 & 10 & 121 & 100 & 110 \\
7 & 12 & 9 & 144 & 81 & 108 \\
\hline Jumlah & $\mathbf{8 4}$ & $\mathbf{8 1}$ & $\mathbf{1 0 2 0}$ & $\mathbf{9 5 3}$ & $\mathbf{9 7 8}$ \\
\hline
\end{tabular}

Sumber : Data Diolah

Dari tabel di atas diperoleh hasil sebagai berikut :

$$
\begin{aligned}
& \mathrm{n}=10 \quad \sum \mathrm{X}^{2}=1.020 \\
& \sum X=84 \quad \sum Y^{2}=953 \\
& \sum \mathrm{Y}=81 \quad \sum \mathrm{X} . \mathrm{Y}=978
\end{aligned}
$$

Kemudian nilai - nilai diatas dimasukkan kedalam rumus koefisien Korelasi sebagai berikut :

\section{Koefisien Korelasi}

$$
\begin{aligned}
& \mathrm{r}=\frac{n \cdot \sum X \cdot Y-\left(\sum X\right) \cdot\left(\sum Y\right)}{\sqrt{n \cdot \sum X^{2}-\left(\sum X\right)^{2}} \sqrt{n \cdot \sum Y^{2}-\left(\sum Y\right)^{2}}} \\
& \mathrm{r}=\frac{7(1.978)-(84) \cdot(81)}{\sqrt{7(1.020)-(84)^{2}} \sqrt{7(953)-(81)^{2}}} \\
& \mathrm{r}=\frac{(12.590)-(12.420)}{\sqrt{(13.550)-(13.225) \cdot \sqrt{(11.900)-(11.664)}}} \\
& \mathrm{r}=\frac{170}{\sqrt{325} \sqrt{236}} \\
& \mathrm{r}=\frac{170}{(18,01) \cdot(15,36)} \\
& \mathrm{r}=0,614
\end{aligned}
$$

Berdasarkan dari hasil perhitungan statistik diperoleh $\mathrm{r}=$ 0,614. Setelah dikonsultasikan dengan standar konservatif untuk mengetahui erat atau tidaknya hubungan tersebut ternyata $r=0,614$ terletak pada jarak antara 0,600 0,799. Hal ini dapat disimpulkan bahwa pengaruh pelatihan terhadap efisiensi kerja karyawan pada Koperasi Setia Usaha OKU Timur adalah mempunyai pengaruh yang kuat.

Untuk mengetahui kadar persentase antara Variabel $\mathrm{X}$ dan kadar prosentase Variabel Y. Maka menggunakan rumus sebagai berikut:

$$
\begin{aligned}
r & =0,614 \\
r^{2} & =0,377 \\
K p & =r^{2} \times 100 \% \\
K p & =(0,377) \times 100 \% \\
K p & =37,00 \%
\end{aligned}
$$

Dengan diketahuinya kadar persentase pengaruh pelatihan sebesar Kp $=37,00 \%$, berarti faktorfaktor lain yang mempengaruhi efisiensi kerja karyawan adalah 100 
$\%$ - Kp $(100 \%-37,00 \%)$ yaitu ada $63,00 \%$. Untuk menguji hipotesis yang telah diajukan maka penulis menggunakan rumus sebagai berikut:

$$
\begin{aligned}
& \frac{r \sqrt{n-2}}{\sqrt{1-r^{2}}} \\
\mathrm{t} \quad & =0,05 \\
\text { alpha }= & \\
\mathrm{t}= & \mathrm{n}-2)=\mathrm{t} 0,05(\mathrm{n}-2) \\
= & \mathrm{t} \quad, 05(7-2) \\
= & \mathrm{t} \quad 0,05(5) \\
\mathrm{t}= & 2,013 \ldots \ldots \text { Dari } \mathrm{t} \text { tabel } \\
\mathrm{r}= & 0,614 \\
\mathrm{r}^{2}= & 0,377 \\
\mathrm{t}= & \frac{0,614 \cdot \sqrt{7-2}}{\sqrt{1-0,377}} \\
\mathrm{t}= & \frac{0,614 \cdot \sqrt{5}}{\sqrt{0,623}} \\
\mathrm{t}= & \frac{0,614(2,828)}{0,789} \\
\mathrm{t}= & \frac{1,737}{0,789} \\
\mathrm{t}= & 2,202
\end{aligned}
$$

Dari hasil perhitungan tersebut diatas dapat diketahui bahwa nilai $\mathrm{t}$ hitung $=2,202$. Sedangkan nilai $\mathrm{t}$ tabel pada tingkat kepercayaan $95 \%$ untuk $(n-2)=1,860$. Maka dapat diketahui nilai $\mathrm{t}$ hitungnya 2,202 lebih besar dari pada nilai $\mathrm{t}$ tabel yaitu $=2,013$, dengan demikian berarti (Ha) dapat diterima dan (Ho) ditolak.

\section{KESIMPULAN DAN SARAN \\ Kesimpulan}

Korelasi antara pelatihan terhadap efisiensi kerja karyawan pada Koperasi Setia Usaha OKU Timur adalah mempunyai pengaruh yang kuat karena di peroleh angka $r$ $=0,614$. Setelah dikonsultasikan dengan standar konservatif ternyata 0,614 terletak antara $0,600-0,799$ yang termasuk pada korelasi kuat. Untuk menjawab hipotesis yang telah dikemukakan pada bab sebelumnya dengan menggunakan rumus uji hipotesa, diperoleh $(\mathrm{t})$ tabel $=2,013$ sedangkan $(\mathrm{t})$ hitung $=2,202$ yang dapat disimpulkan bahwa ( $\mathrm{t}$ ) hitung $>(\mathrm{t})$ tabel atau $(\mathrm{t}$ hitung lebih besar dari t tabel), sehingga hipotesis yang diajukan pada bab sebelumnya terbukti atau Ha diterima dan Ho ditolak, karena korelasi yang ada adalah kuat.

\section{Saran}

Berdasarkan kesimpulan penelitian maka disarankan:

1. Pelaksanaan program pelatihan kerja karyawan yang telah terlaksana secara baik diharapkan mampu menjadi pendorong untuk peningkatan efisiensi kerja karyawan kearah yang lebih baik .

2. Besarnya pengaruh yang diberikan oleh program pelatihan terhadap efisiensi kerja karyawan diharapkan menjadi salah satu 
pertimbangan bagi pimpinan koperasi untuk tujuan peningkatan efisiensi kerja para karyawan tersebut.

3. Faktor pelatihan karyawan merupakan faktor yang tidak boleh diabaikan dalam aktivitas perusahaan saat ini. Oleh karena itu hendaknya pemberian program pelatihan bagi karyawan perlu dipertahankan bahkan lebih ditingkatkan agar efisiensi kerja karyawan yang telah ada dapat dipertahankan ataupun lebih ditingkatkan.

4. Untuk lebih memaksimalkan performance kerja karyawan, maka pemberian pelatihan sebaiknya disesuaikan dengan tujuan perusahaan.

\section{DAFTAR PUSTAKA}

A.A. Anwar Prabu Mangkunegara, Perencanaan dan Pengembangan Sumber Daya Manusia, PT. Refika Aditama, Bandung, 2003.

J. Supranto, Statistik Teori dan Aplikasi, Erlangga , Jakarta, 2000

Malayu SP. Hasibuan, Manajemen Sumber Daya Manusia, Bumi Aksara , 2000

Mulyamah. (1987). Manajemen Perubahan. Jakarta : Yudhistira.

Soekidjo

Notoatmojo, Pengembangan Sumber Daya Manusia, Rineka Cipta, Jakarta, 2003
Yayat Herujito, Dasar-Dasar Manajemen, Grasindo, Jakarta, 2001

Sulistiyani,Ambar Teguh dan Rosidah,2003, Manajemen Sumber daya manusia konsep teori Pengembangan dalam konteks Organisasi Publik, Graha ilmu Jakarta.

Gomes, Faustino Cardoso ( 2003), Manajemen Sumber Daya Manusia, Andi Jogyakarta

Mangku

Prawira

Syafri,2002,Manajemen

Sumber D Daya manusia,Penerbit Ghalia Indonesia,Jakarta 